\title{
Nutritional quality of organic food: shades of grey or shades of green?
}

\author{
Christine M. Williams \\ Hugh Sinclair Unit of Human Nutrition, School of Food Biosciences, University of Reading, Reading RG6 6AP, UK
}

\begin{abstract}
Consumer concern regarding possible adverse health effects of foods produced using intensive farming methods has led to considerable interest in the health benefits of organically-produced crops and animal products. There appears to be widespread perception amongst consumers that such methods result in foods of higher nutritional quality. The present review concludes that evidence that can support or refute such perception is not available in the scientific literature. A limited number of studies have compared the nutrient compositions of organically- and conventionally-produced crops, with a very small number of studies that have compared animal products (meat, milk and dairy products) produced under the two agricultural systems. Very few compositional differences have been reported, although there are reasonably consistent findings for higher nitrate and lower vitamin C contents of conventionally-produced vegetables, particularly leafy vegetables. Data concerning possible impacts on animal and human health of diets comprising organic or conventional produce are extremely sparse. Data from controlled studies in animal models, particularly within single species, are limited or poorly designed, and findings from these studies provide conflicting conclusions. There are no reports in the literature of controlled intervention studies in human subjects. Comparison of health outcomes in populations that habitually consume organically- or conventionally-produced foods are flawed by the large number of confounding factors that might contribute to any differences reported. If consumer perceptions regarding potential health benefits of organic foods are to be supported, more research of better quality is needed than that which is currently available.
\end{abstract}

\section{Organic foods: Nutritional quality: Scientific studies}

Organic food is derived from crops or animals produced in a farming system that avoids the use of man-made fertilisers, pesticides, growth regulators and livestock feed additives (Institute of Food Science and Technology, 1999). Organic farming systems rely on crop rotation, animal and plant manures, some hand weeding and biological pest control. Although the organic farming movement in the UK dates back to the Second World War (Daldy, 1940), there has been a marked increase in the demand for organic foods over the past 5-10 years, with consequent growth of this niche market. At least in part, this demand appears to reflect consumer concern regarding the safety of food produced under intensive farming systems. A recent House of Lords Select Committee on European Communities (1999) report concluded that healthiness is a prime factor contributing to the willingness of the public to pay premium prices for organic food. In the UK MORI (Wright, 1997) reported that $60 \%$ of the population would choose organic food if it was easily available and cost no more than conventional food.
Despite the widespread conviction held by the public that organic food is 'healthier' than foods produced using conventional farming, evidence to support this perception is difficult to identify. This difficulty arises because very limited research has been conducted and much of the available scientific data is out-dated or based on inadequate study designs.

The view that organic foods are 'healthier' than conventionally-produced foods appears to be based on the perception that organic foods have superior sensory attributes, contain lower levels of pesticides and synthetic fertilisers and have higher levels of nutrients and protective phytochemicals. Conversely, it has also been suggested that application of manure and reduced use of fungicides and antibiotics in organic farming could result in a greater contamination of organic foods by microorganisms or microbial products. These wider food safety and quality aspects have recently been reviewed elsewhere (Tinker, 2001). The present review will confine itself to 
consideration of the scientific literature concerning effects of growing conditions on the nutritional quality of foods. However, brief consideration will also be given to the issue of pesticide residue levels, since these levels might be expected to have some impact on nutrient levels. Clearcut conclusions cannot be drawn from the present review, since very few of the studies conducted to date adhere to ideal criteria for evaluating effects of the two growing systems on nutritional quality. Such evaluations will only allow unequivocal interpretation if they involve identical strains of plants or animals grown and stored under otherwise similar conditions (e.g. light exposure). Unfortunately, few of the studies reviewed in the present chapter can be considered to fulfil these rigorous criteria.

\section{Effect of agricultural methods on nutritional quality}

The developing popularity of organically-grown foods has originated, in part, from an increasingly widespread perception that this production method results in food of higher nutritional quality. However, evidence that can clearly support or negate this perception remains equivocal, with the number of systematically-controlled studies that have compared organic $v$. conventionally-grown crops being very small. The extent of disagreement is well illustrated by two diametrically-opposed statements currently published on the web. Whereas an editorial on the website of the American Council on Science and Health (Klurfeld, 2000) states 'Not a single published study has shown any difference in the nutrient content of organic versus conventional farm produce', the Mothernature site (www.mothernature.com) supports the view that organic food is healthier than conventionally-grown food '.. based on research in Denmark and Germany showing that organically grown foods contain higher levels of nutrients.' Three scientific reviews of the published literature in this area in recent years have failed to draw definitive conclusions (Lampkin, 1990; Woese et al. 1997; Worthington, 1998), although each of the reviews indicates trends for higher concentrations of some nutrients in organic produce compared with conventionally-grown produce. The Worthington (1998) review also concludes that the evidence for adverse effects of conventional feeds on animal health is fairly strong.

The present review will evaluate evidence for differences in the nutritional quality of conventionally-grown $v$. organic produce based on three types of study:

nutrient analyses of crops grown under the different conditions;

health outcomes in controlled animal feeding studies;

consideration of a small number of observational and controlled intervention studies in human subjects.

\section{Comparison of nutrient composition of organic and conventional crops}

Woese et al. (1997) considered over 150 comparisons of conventionally- and organically-produced foods published between 1924 and 1994. Although on superficial examination their review would appear to represent a substantial body of knowledge, the authors drew attention to the serious shortcomings of many of the studies, the limited background information in the papers and the lack of rigorously-controlled conditions. The majority of studies reported are derived from the German literature, with a substantial number representing output from dissertations. The extent to which the reports have undergone rigorous peer review is debatable. Many studies compared produce available in markets where the validity of the 'organic' produce could not be confirmed. The long period of the review (1924-1994) also means that growing conditions for the foods classified as 'conventionally-grown' are likely to have varied considerably over time, due to changes in agricultural practice.

The review concentrated on food groups, including cereals, potatoes, vegetables, fruits, bread, cakes, milk and meat. In some cases a sufficient number of studies were available for comparison, e.g. for cereals there were thirty studies, for vegetables seventy studies and for potatoes twenty-two studies. Fewer studies were available for animal products, with nine studies on milk and only four on meat, all of which were for pork. With respect to the studies on crops, there was clear evidence for higher nitrate concentrations in vegetables grown under conventional conditions, although this information mainly related to green leafy vegetables and did not apply to cereals or potatoes.

No differences were found in the mineral, trace element or B vitamin levels of organically- or conventionally-grown cereals, potatoes or vegetables. Also, in twenty-seven comparative studies conducted on vegetables no differences were found in levels of vitamin A or $\beta$-carotene. However, there was moderately strong and consistent evidence for lower levels of vitamin $\mathrm{C}$ in conventionally-grown potatoes, and $50 \%$ of the studies conducted on vegetables also showed organic produce to have higher vitamin $\mathrm{C}$ levels, with the remainder showing no difference. There were no studies that showed lower levels of vitamin $\mathrm{C}$ in organic potatoes or vegetables. Evidence for higher levels of vitamin $\mathrm{C}$ in organic produce was particularly strong for leafy vegetables. These vegetables also tended to have higher $\mathrm{DM}$, so that the higher vitamin $\mathrm{C}$ levels might reflect the lower water content of organic produce. Lampkin (1990) also noted evidence for higher vitamin $\mathrm{C}$ levels in organic vegetables (28\%) associated with higher DM values $(23 \%)$, although yield was $24 \%$ lower for organic produce compared with conventionally-grown produce. Lampkin (1990) emphasised the 12-year comparative study of Schupan (1975), which showed higher concentrations of protein, vitamin $\mathrm{C}, \mathrm{Fe}, \mathrm{K}, \mathrm{Ca}$ and $\mathrm{P}$ and lower levels of $\mathrm{Na}$ in organic vegetables.

Worthington (1998) evaluated thirty-four publications that had compared effects on the nutrient content of crops of organic $v$. conventional management. As in the case of the Woese et al. (1997) review, the author emphasised the mixed nature of the data. Some studies provided clear comparisons between organic and conventional farming, other studies examined combinations of farming practices and systems. The source of samples varied, and included controlled research plots, working farms, storage facilities and retail outlets. In general, the findings support the overall conclusions drawn from the Woese et al. (1997) review, and a number of the studies are common to both. The clearest 
Table 1. Comparison of protein, nitrate and selected vitamin and mineral contents of organic $v$. conventionally-grown crops (derived from Worthington, 1998)

\begin{tabular}{lrrr}
\hline Nutrient & Increased & Same & Decreased \\
\hline Protein quality & 3 & 0 & 0 \\
Nitrate & 5 & 10 & 25 \\
Vitamin C & 21 & 12 & 3 \\
$\beta$-carotene & 5 & 5 & 3 \\
B vitamins & 2 & 12 & 2 \\
Ca & 21 & 20 & 6 \\
Mg & 17 & 24 & 4 \\
Fe & 15 & 14 & 6 \\
Zn & 4 & 9 & 3
\end{tabular}

(No. of studies of organic crops shown to have increased, decreased or same nutrient content compared with conventionally-grown crops)

data were for nitrate levels which were higher, and vitamin $\mathrm{C}$ levels which were lower, in conventional produce compared with organic produce. Twenty-five of forty-one studies showed higher levels of nitrate and twenty-one of thirty-six studies showed lower levels of vitamin C. Data were insufficient or inconclusive for most of the other vitamins analysed. In the case of minerals and trace elements levels found in organic produce tended to be either higher or the same as in conventional produce, with few studies showing lower levels in vegetables of organic origin (Table 1).

Lampkin's (1990) review, which concluded favourably on the benefits of organic production, is less critical of the limited nature of the available data than those of Woese et al. (1997) and Worthington (1998), and does not adequately address the scientific limitations of the comparative studies conducted to date. His review, as well as that of Woese et al. (1997), refers to the use of "photon emission measurements' to compare the quality of organic and conventionally-produced foods. This method appears to measure the intensity of light energy emitted by plant cells. A number of studies conducted at the Elm Farm Research Centre, Newbury, Berks., UK (Elm Farm Research Centre, 1989), have used this method to demonstrate that organically-produced foods (e.g. carrots, onions) show higher photon emission than conventional produce. However, despite the claimed scientific credibility of this approach, it would undoubtedly be questioned with respect to its validity as a means of quantifying the nutritional quality of food. A statement made to support the relevance of photon emission findings reads: 'The higher level of light energy that a cell emits the greater its vitality and the potential for transfer of its energy to the individual that consumes it.' This statement and also one which refers to DNA 'as the source of light energy in plants', has no basis in science and does not accord with currently-accepted concepts of cell, food and human energy metabolism. In contrast, it is disappointing to note the complete lack of comparative studies of levels of plant phytochemicals in organic $v$. conventionally-grown produce. The considerable interest in potential protective health effects of non-nutrient components of foods, including flavonoids, phyto-oestrogens and glucosinolates, suggests a potent mechanism by which the two growing systems could yield plants of varying nutritional quality. Many of these components are produced by plants as stress responses or protective mechanisms against harmful pests or adverse growing conditions. It might therefore be expected that growing systems that differ considerably with respect to plant exposure to stressed conditions would lead to differences in the contents of these potentially-protective compounds. Future research in this area is not only warranted, but essential if credible scientific data that can support the possibility of enhanced nutritional properties of organic crops is to be provided to consumers.

Although there are serious limitations in the quantity and quality of the data described earlier, the reviews of both Woese et al. (1997) and Worthington (1998) show a trend for organic produce to have a higher nutrient content than conventional produce. However, although the weight of evidence at the present time is suggestive of higher nutrient quality of organic produce, this finding does not seem to apply to all nutrients or all crops, and further research of better quality than that currently available is needed to confirm these tentative conclusions. Some data may be explicable in terms of the reported higher water content of conventional crops. However, if this finding represents the major explanation, then a more consistent effect on levels of all the nutrients would be expected to be seen. The most consistent data are those available for vitamin $\mathrm{C}$ and nitrate, which support beneficial effects of organic production on levels of these nutrients.

\section{Effects of agricultural methods on animal health}

Few controlled intervention studies have compared effects of organic and conventionally-grown feeds on animal health in the long term, and many of the studies reported in the literature are extremely dated. Indeed, some of the studies were originally conducted in the 1920s and 1930s by scientists investigating 'essential growth factors' or vitamins. The early work of McCarrison (1926) showed that doves fed a supplement of millet grown using different types of fertiliser showed marked differences in weight gain over a period of 2 months. The best growth performance was seen in doves fed millet grown under cattle manure, whilst millet grown under mineral fertiliser supported much lower growth rates. Table 2 summarises studies conducted between 1926 and 1992 that have assessed either weight or reproductive performance of rodents or rabbits fed organic or conventionally-grown feed. As in the case of the nutrient composition data, caution should be used in placing excessive reliance on the findings, some of which have been published only in the form of results from dissertations. Insufficient data is available to present summary tables for species other than rodents and rabbits. Reproductive performance is generally considered a robust environmental health indicator because it is less affected by genetic determinants than other outcomes.

Only one study (Scheunert et al. 1934) observed worse performance in organically-fed animals (rats), although Scott et al. (1960) showed mice fed a mixed organic and conventional feed had poorer reproductive performance than those raised either on conventional or organic feed alone. A majority of the studies found that animals given 
Table 2. Comparison of weight gain and reproductive performance in rodents and rabbits fed organic or conventionally-grown feed

\begin{tabular}{lll}
\hline Species & Study & Animals fed organic feeds showed: \\
\hline Rats and mice & McCarrison (1926) & Greater weight gain \\
& Rowlands \& Wilkinson (1930) & Superior weight gain \\
& Scheunert et al. (1934) & Shorter lifespan, worse health \\
& Miller \& Dema (1958) & No difference in weight gain or reproduction \\
& Scott et al. (1960) & Better reproduction with organic feeds; worst performance with mixed \\
& organic and conventional feed
\end{tabular}

organic feed fared better than those fed conventional feed. However, there is little internal consistency, even amongst the studies that have shown beneficial findings. Whereas some of the earlier studies in rabbits found clear evidence for reduced egg production and abnormal histology in conventionally-fed animals (Hahn et al. 1971; Aehnelt \& Hahn, 1973), other studies did not (Bram, 1974; Alter 1978; Meinecke, 1982). One of the criticisms of the earlier studies is that the nutrient compositions of the diets were frequently different between the two groups. Recent studies have provided more rigorously-controlled nutrient conditions (Gottschewski, 1975; Edelmuller, 1984; Staiger, 1986). However, even these studies have not demonstrated concordant findings, with some of the studies showing higher pregnancy and birth rates (Staiger, 1986), whereas in other studies beneficial effects of organic feeds on numbers of live births were the dominant findings (Edelmuller, 1984). The more recent studies in rodents have also tended to observe greatest effects on numbers of stillborn animals and on perinatal mortality (Neudecker, 1987; Velimirov et al. 1992).

Based on the data available from controlled animal feeding studies, there appears to be modest evidence to suggest that organic feed may have beneficial effects on animal health, particularly with respect to reproduction and pregnancy outcome. However, the small number of studies, the variability in the study designs and the dated nature of much of the animal work suggests conclusions cannot be drawn at the present time. The lack of internal consistency in the data is of particular concern. Furthermore, it is not at all clear from these studies whether any differences in reproductive performance that might exist can be attributed to differences in nutritional status of the animals, or whether the data reflect adverse effects of pesticide residues or other chemicals. The very small differences in nutrient contents of crops grown under the two systems that were discussed earlier (p. 20) would be very unlikely to provide a nutritional basis for the differences in reproductive performance in these animals.

\section{Effects of agricultural methods on human health}

There have been no post-war controlled studies that have compared effects of organic and conventional products on human health; such studies pose considerable problems of feasibility, cost and ethics. They would need to be carried out under very carefully controlled conditions over long periods of time, thereby limiting the number and type of subjects who would be eligible and available for study. A few observational studies of sperm quality in organic and non-organic farmers have been published, with one study showing lower semen counts in conventional farmers than organic farmers and the other study showing no difference between the two groups (Jensen et al. 1996; Juhler et al. 1999). A few experiments conducted in Germany in the 1930s and 1940s compared effects on human health of foods produced using either organic or mixed (organic plus chemical) fertilisers. No effects were observed in experiments involving 260 adolescents (Wendt, 1943) or 300 adults (Reiter et al. 1938). In later studies crops grown with mixed fertilisers were found to have more $\beta$-carotene and minerals but lower levels of B vitamins than crops grown organically. No effects of these products on blood variables were observed in adults, although in infants there was a higher daily growth rate and higher serum $\beta$-carotene in children fed on crops grown under mixed fertiliser conditions (Dost \& Schupan, 1944; Schupan, 1972). Lack of relevant dietary data, heterogeneity in the study populations and limited information on growing conditions of the foods used means that much of this early data cannot be scrutinised according to current scientific criteria. For this reason no valuable inferences or interpretations can be derived from these studies.

\section{Conclusions}

There have been very few scientific studies in which foods grown conventionally have been compared, under comparable and controlled conditions, with those produced organically, in terms of their nutrient composition or their 
biological effects on animals or human subjects. It would appear that few differences can be demonstrated, and where differences are detected they are very small.

Some studies have shown slightly enhanced levels of certain micronutrients, e.g. vitamin $\mathrm{C}$ content, in organic foods compared with foods grown conventionally. In part this finding may be ascribed to higher water content in some conventionally-grown foods. It is unlikely that small differences in nutrient content would have health implications for consumers. Future studies that can evaluate effects of growing conditions on levels of protective phytochemicals are urgently required.

Animal studies that have been conducted to compare health effects of conventionally- and organically-grown produce are very limited in number and have involved only a few species. Limitations in the study designs and lack of internal consistency in the findings mean that the present data are of limited value in providing a scientific basis for evaluating health effects of organic foods.

There are virtually no studies of any size that have evaluated effects of organic $v$. conventionally-grown foods on human health. Observational studies that have been conducted to compare the health profiles of organic and conventional farmers are of questionable value because of the possibility of confounding by other lifestyle factors.

The quality and quantity of the science applied in this area to date is inadequate. Conclusions cannot be drawn regarding potentially beneficial or adverse nutritional consequences, to the consumer, of increased consumption of organic foods.

\section{References}

Aehnelt E \& Hahn J (1973) Fertility of animals - a means to test organic food and feed stuff? Tierarztliche Umschau 28, 155-160.

Aehnelt E \& Hahn J (1978) Animal fertility: a possibility for biological quality assay of fodder and feeds. Biodynamics 25, $36-47$.

Alter G (1978) Effect of dietary factors on fertility, vitamin C content and the histology of the ovary in female rabbits. Dissertation, Tierarztliche Hochschule, Hannover, Germany.

Bram L (1974) Effect of dietary factors on fertility, vitamin $\mathrm{C}$ content and the histology of the ovary and adrenal gland in female rabbits. Dissertation, Tierarztliche Hochschule, Hannover, Germany.

Daldy Y (1940) Food production without artificial fertilisers. Nature 145, 905-906.

Dost FH \& Schupan W (1944) Experiments with vegetables produced with different fertilizers. Ernährung (Leipzig) 9, 581-586.

Edelmuller I (1984) Quality of food - produced organically or with conventional methods - feeding studies in rabbits. Dissertation, University of Vienna, Austria.

Elm Farm Research Centre (1989) Quality of Organically Produced Foods. Proceedings of International Scientific Colloquium February 1989. Newbury, Berks.: Elm Farm Research Centre.

Gottschewski GHM (1975) New toxicological methods to study pesticides and herbicides. Plant Foods for Human Nutrition 25, 21-42.

Hahn J, Aehnelt E, Grunert E, Schiller H, Lengauer E, Schulz L-Cl \& Pohlenz J (1971) Effect of organically and conventionally produced hay on uterus and ovary health. Deutsche Eierarztliche Wochenschrift 78, 114-118.
House of Lords Select Committee on European Communities (1999) House of Lords Select Committee on European Communities Sixteenth Report. Organic Farming and the European Union. London: The Stationery Office.

Institute of Food Science and Technology (1999) Position statement: organic food. www.ifst.org

Jensen TK, Giwercman A, Carlsen E, Scheike T \& Skakkebaek NE (1996) Semen quality among members of organic food associations in Zeland Denmark. Lancet 347, 1844.

Juhler RR, Larsen SB, Meyer O, Jensen ND, Spano M, Giwercman A \& Bonde JP (1999) Human semen quality in relation to dietary pesticide exposure and organic diet. Archives of Environmental Contamination and Toxicology 37, 415-423.

Klurfeld DM (2000) Organic food: food for thought? http://www.acsh.org/press/editorials/organicfood021700.html

Lampkin N (editor) (1990) The wider issues. In Organic Farming, pp. 557-611. Ipswich, Suffolk: Farming Press.

McCarrison R (1926) The effect of manurial conditions on the nutritive and vitamin values of millet and wheat. Indian Journal of Medical Research 14, 351-378.

McSheehy TW (1977) Nutritive value of wheat grown under organic and chemical systems of farming. Qualitas Planitarum 27, 113-123.

Meinecke B (1982) Effect of conventionally and organically produced feed stuff on the fertility of rabbits. Zentrablatt für Veterinarmedizin 29, 5-15.

Miller DS \& Dema IS (1958) Nutritive value of wheat from the Rothamsted Broadbalk field. Proceedings of the Nutrition Society 17, xliv-xlv.

Neudecker C (1987) Studies in Animals on the Effect of Conventional and Organic Potatoes and Carrots, pp. 110-125. Tutzing, Germany: Akademie für Politische Bildung.

Reiter H, Ertel H, Wendt H, Pies Prufer J, Barth L, Schroder H, Catel W, Dost FH \& Scheunert A (1938) Nutritional studies on the effect on vegetables produced with and without fertilizers. Emährung (Leipzig) 3, 53-69.

Rowlands MJ \& Wilkinson B (1930) Vitamin B content of grass reeds in relation to manures. Biochemistry Journal 24, 199-204.

Scheunert A, Sachne M \& Speche R (1934) Efficacy of food produced with and without fertilizer. Biochemistry Journal 274, 372-396.

Schupan W (1972) Effects of the application of inorganic and organic manures on the market quality and on the biological value of agricultural produce. Qualitas Planitarum 21, 381-398.

Schupan W (1975) Yield maximisation versus biological value. Qualitas Planitarum 24, 281-310.

Scott PP, Greaves JP \& Scott MG (1960) Reproduction in laboratory animals as a measure of the value of some natural and processed foods. Journal of Reproduction and Fertility 1, 130-138.

Staiger D (1986) Effect of conventional and organic feed stuff on fertility, health, and meat quality in rabbits. Dissertation, Rheinische Friedrich Wilhelms Universität, Bonn, Germany.

Tinker PB (editor) (2001) Shades of Green: A Review of UK Farming Systems. Stoneleigh Park, War.: Royal Agricultural Society of England.

Velimirov A, Plochberger K, Huspeka U \& Schott W (1992) The influence of biologically and conventionally cultivated food on the fertility of rats. Biological Agriculture and Horticulture 8 , $325-337$.

Wendt H (1943) Long term studies in humans on the effect of vegetables and potatoes produced with different fertilizers. Ernährung (Leipzig) 8, 281-295.

Woese K, Lange D, Boess C \& Bogl KW (1997) A comparison of organically and conventionally grown foods - results of a review of the relevant literature. Journal of the Science of Food and Agriculture 74, 281-293. 
Worthington V (1998) Effect of agricultural methods on nutritional quality: a comparison of organic with conventional crops. Alternative Therapies 4, 58-68.
Wright S (1997) Europe goes organic. Food Ingredients Europe 3, 39-43. 